\title{
USE OF “VIRTUAL” FIELD TRIPS IN TEACHING INTRODUCTORY GEOLOGY
}

\author{
STEPHEN D. HURST* \\ Department of Geology, University of Illinois, 1301 W. Green St., Urbana, IL 61801, U.S.A.
}

(Received 13 October 1997; revised 20 November 1997)

\begin{abstract}
We designed a series of case studies for Introductory Geology Laboratory courses using computer visualization techniques integrated with traditional laboratory materials. These consist of a comprehensive case study which requires three two-hour long laboratory periods to complete, and several shorter case studies requiring one or two, two-hour laboratory periods. Currently we have prototypes of the Yellowstone National Park, Hawaii volcanoes and the Mid-Atlantic Ridge case studies. The Yellowstone prototype can be used to learn about a wide variety of rocks and minerals, about geothermal activity and hydrology, about volcanic hazards and the hot-spot theory of plate tectonics. The Hawaiian exercise goes into more depth about volcanoes, volcanic rocks and their relationship to plate movements. The Mid-Atlantic Ridge project focuses on formation of new ocean crust and mineral-rich hydrothermal deposits at spreading centers. With new improvements in visualization technology that are making their way to personal computers, we are now closer to the ideal of a "virtual" field trip. We are currently making scenes of field areas in Hawaii and Yellowstone which allow the student to pan around the area and zoom in on interesting objects. Specific rocks in the scene will be able to be "picked up" and studied in three dimensions. This technology improves the ability of the computer to present a realistic simulation of the field area and allows the student to have more control over the presentation. This advanced interactive technology is intuitive to control, relatively cheap and easy to add to existing computer programs and documents. (C) 1998 Elsevier Science Ltd. All rights reserved
\end{abstract}

Key Words: Virtual field trip, Teaching, Introductory geology, Interactive, Field.

\section{INTRODUCTION}

Geologists have long used a kind of case study, the field trip, to educate both students and professionals. Due to the remarkable diversity of the natural features of Earth, and the need to integrate many physical and logical principles to interpret those features, geology requires a life-long apprenticeship whereby students and professionals alike learn by observing and working with other geologists having greater experience and different areas of expertise. Trips to diverse geological settings over the course of a geologist's career provide breadth of experience and depth of understanding of the geological processes of the earth.

A field trip is a planned journey through a region to illustrate some basic and specific geological phenomena and relationships. Field relationships are crucial to understanding geologic events and much of the value of a field trip lies in the integration of data taken at a variety of scales and locations. For these reasons the field trip is an apt metaphor for the kind of geologic case study that can be used in the teaching of introductory geology laboratories.

*E-mail: shurst@uiuc.edu.
However, at this time of tight budgets and greater time constraints, teaching undergraduate students by taking them on multiple field trips is increasingly difficult for teachers. At the same time, computer hardware and software is maturing to a state where "virtual" visits to geologic sites may provide some of the information and interaction that are frequently acquired during real field trips. Therefore, we have experimented with creating and using these "virtual" field trips to teach geology to students.

A geologic field study may be broken down into four fundamental tasks: examining the field area to observe and gather data in reconnaissance fashion; formulating hypotheses regarding the geologic history of the area; gathering additional data to test the hypotheses; and reporting the results. Guided field trips often mimic the first three of these same activities. Each of the four tasks may be simulated to a greater or lesser extent on a computer. We translate the field trip experience into an electronic format by assembling images and data into a coherent scheme that allows easy access to data, extraction of data for analysis, and recording of results and conclusions. Computers excel at storing and presenting vast quantities of data necessary to a field trip or case study. Therefore we see a computerized field trip as a valuable aid to teaching which 
makes more data available and gives the student more control over the form, display and analysis of the data.

\section{HISTORY AND IMPLEMENTATION}

Given that field work and field trips are important to the training and practice of geology, many replacements for actual field work have been tried in educational settings. Among the most popular of these are the slide show and laboratory courses consisting of the study of rock specimens and geologic maps. Some institutions have also tried to create field trips as movies or more recently, videotapes. The Geological Society of America and the Open University in U.K. are putting significant resources into creating videotape "field trips". This type of presentation has the advantage of strong visual appeal and full-motion presentation of graphics but lacks interaction with the student. As we conceive it, the computerized field trip should not be just a slide show of various kinds of information, but should also require the extraction and analysis of that data in an interactive way.

In an early attempt to create a teaching aid with more student interaction, Optical Data Corporation created a series of videodiscs containing still images and motion clips that are designed to be controlled by a Hypercard $(\mathbb{M})$ interface. The original system, including an earth science disc, was introduced simultaneously with Hypercard(II) 1.0 in 1987 and has been subsequently upgraded. With the software and disc a teacher can create an interactive yet guided lesson for the student (Harper, 1990). This system allows interaction only to the extent that the student can control what is shown but cannot extract, modify or add to the data or interpretations. In addition, the system is a hybrid grafting of videodisc technology and a controlling computer. Optimally, the interactive system should consist of a nonhybrid, single-base platform for reasons of simplicity and compatibility.

Research is also continuing on systems that are substantially similar to what we have worked on in other disciplines such as anatomy. The Vesalius Project at Colorado State University created a computerized anatomy laboratory. That project involved digitizing a human cadaver and placing it into a software system that allows beginning students to "dissect" the body (Roper, 1989). With electronic dissection, any group of tissues can be viewed from any angle the student selects and relationships between different systems can be shown by a keystroke command. The computerized dissection or tour is in many ways analogous to our proposed field trips. More recently in the discipline of geology, Condit (1995) has created a "dynamic" geologic map that provides far greater access to in- formation about the mapped area than the printed version.

Since around 1994, the explosive growth of the Internet and the World Wide Web has made it the dominant method of providing hypermedia content. Continuous improvements in browser and server software have made the WWW competitive with stand-alone programs in the variety of media content that the Web can provide. With Java applets, various plug-ins to browsers and other improvements the Web can now provide audio, video and other types of media to a limited extent in near real time. A variety of Web-based "field trips" now exist and are available to students (for example see the links at 〈http://www.uh.edu/ jbutler/anon/ anontrips.html $\rangle$ ).

\section{OBJECTIVES}

The objectives of this project are to teach a broad spectrum of students geologic principles and factual information in the context of case studies using state-of-the-art information technology. The introductory laboratories emphasize the multidisciplinary nature of earth science, hypothesis formulation and testing the hypotheses. We decided on a series of case studies utilizing computerized field trips integrated with more traditional laboratory materials. The course curriculum consists of one case study (Yellowstone) which requires three twohour long laboratory periods to complete, and several shorter case studies requiring one or two, twohour laboratory periods. Usually students start by familiarizing themselves with the area using satellite images, aerial photographs, topographic maps, and limited geologic data. The student becomes familiar with the exposed rock types in the area. Additional information is provided in the form of maps and rock samples the student can handle. Students are then asked to formulate hypotheses about the geologic history of the area, and propose ways to test those hypotheses. The next phase has the student acquire additional information, such as earthquake data, geochemical data, radiometric dates, additional field mapping, and other site specific information. The final phase is analysis of the data and refinement of existing or formulation of new hypotheses. The student then reports the results and discusses the hypotheses.

\section{BACKGROUND}

Initially faculty and students at Duke University created 18 interactive "virtual" field trips using Supercard $(\mathrm{II})$ software on Macintosh $\mathrm{II}$ computers. This was a first test of the concept and we encouraged experimentation with style, subject and presentation. These first experiments were edited to some extent and placed on a CD-ROM. One hundred 
copies of the CD-ROM were manufactured and given away at the national Geological Society of America meeting in 1992 for evaluation and use by geoscience teachers (Hurst, Perkins and Karson, 1992).

During the next year, using evaluations of these first field trips we created several more "virtual" field trips. We also simplified and made more consistent the computer interface to the field trips. Again we manufactured and distributed a second edition of the "Geologic Field Trips" CD-ROM. Although all recipients were expected to return evaluation forms and comments, in fact, we received few back from the community. Based on the few we did receive and evaluations by students and faculty that we had used the software at Duke and University of North Carolina, we decided to change the original conception of teacher modifiable modules that could be added to existing curricula. We decided to develop more complete laboratory exercises with the computer field trips integrated directly into the course. This meant adding significant amounts of information, developing computer exercises to use the added data and putting the field trips into a framework where they could be used to advantage in the lab course.

The result was to concentrate initially on three field trips to build them up into case studies that could be used with ancillary materials such as rock specimens and maps to form the basis of at least half a semester of labs. Field trips to Yellowstone National Park, the volcanoes of Hawaii, and the Mid-Atlantic Ridge were used as the core case studies because they provide a good introduction to large-scale concepts of plate tectonics. Yellowstone in particular has good examples of many other geologic processes and features, and materials were relatively easy to obtain.

The Mid-Atlantic Ridge "field trip" is another example which encompasses a variety of geologic processes including igneous rock formation, normal and strike-slip faulting, seismicity at plate boundaries, sedimentation, development of chemosynthetic biological communities around black smokers, and how black smokers regulate ocean chemistry (all in a sufficiently simplified format).

\section{NUTS AND BOLTS}

The virtual field trips were originally created in the hypermedia program Supercard(II), a generally more capable program than the original Apple Hypercard(IM. Supercard was selected, not because of any one advantage over competing programs but because of the overall combination of features of the program. Its full-featured scripting language is an easy-to-learn superset of Hypercard; indeed Hypercard stacks can be easily converted to Supercard. It has support for multiple windows, color, resources, and has two more object types than Hypercard. Each card (or screen) may have a color palette associated with it. It has several tools that are convenient for making interactive maps and includes both vector and pixmap drawing tools. The scripting language is robust and allows for almost any programming need. QuickTime movies and QuickTime VR scenes are also supported. Supercard was also less expensive than most of the alternatives, a consideration when we were expecting other teachers to take and modify our field trips. The versatility provided by the programming language is also a disadvantage in that a significant amount of programming had to be done by a developer reasonably proficient to get any interactive behavior in the field trips. The company that makes Supercard has promised a version for Windows although it is not available at this time.

After the first year we decided on a standard set of navigation buttons and introductory cards. These cards include a title card, a table of contents, a flowchart card, a field-trip stop map, a help card, a glossary and a card with all the references. The buttons allow the user to go to the next card in the sequential order put together by the creator, to go back one card in the sequential order, to return to the card most recently shown, to go to the table of contents, the flowchart, the help card, or to quit the program. Easily navigating through the virtual field trip is crucial to students. The variety of navigation aids such as the flowchart and map is intended to enable users to find the topic they want quickly and easily.

Adding interactivity to the field trips must be done programmatically in Supercard. Each object may have a script associated with it, including images, text fields, cards, windows and even the overall project itself. Text data must be stored in text fields which can be accessed by name and then by individual line, word or even character. Therefore to associate a piece of data with an image or graphic object requires a script to match the part of the text field with the graphic. Creating plots or other interactive exercises where the user gets to select the data, therefore often needs substantial scripting and expert construction and design. Supercard also does not have multicell tables for storing data, although they could be mimicked using a set of text lists.

\section{BENEFITS AND DISADVANTAGES OF COMPUTER FIELD TRIPS}

The hype and speculation about what is called Virtual Reality may give a rosy picture of the future of virtual field trips. At the present state and for the foreseeable future, computer technology just does not have the power or "intelligence" to completely substitute for human interaction. Even 
Table 1. Computer advantages

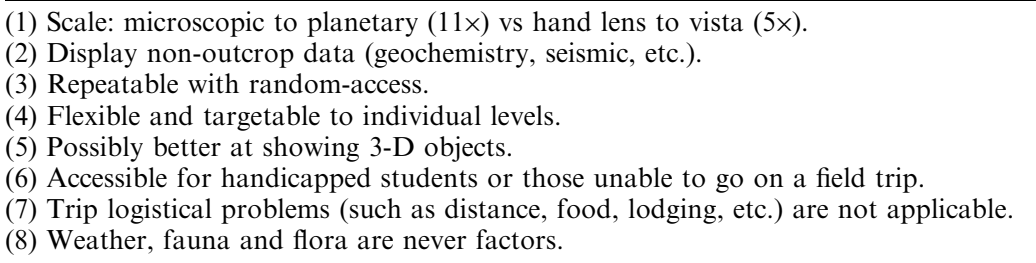

e-mail communication, generally considered to be one of the great advances in information technology, does not have all positive repercussions (see study at $\langle$ http://www.ncsa.uiuc.edu/Edu/trg/email//). Nevertheless, studies have shown that certain types of computer assisted learning do seem to work (Kulik, 1994). Table 1 summarizes the advantages that we see in computerized field trips.

Probably the most important advantage of an individual computerized field trip is that the computer can present data at a variety of scales. A field trip is conducted at one scale, the roadside outcrop scale, yet often information available only from microscopic examination or satellite photos must be conveyed. The computer has the advantage that highly diverse types of data are all instantly available without returning to the field, laboratory or library.

We also believe that use of the computerized "field trips" will promote three-dimensional visualization which is a very important skill for the geologist to master. The computer can present images from a variety of viewpoints (aerial view, cross-sectional view, animated rotating block diagrams) and at many different scales so that relationships that are difficult to see even in the field are made clear.

Unfortunately, every student actually falls into the sixth category item in Table 1 , because some field trips (to the moon, to the ocean floor, and to other inaccessible areas) are restricted to a very few visitors and others are just logistically difficult for the majority of students. In addition, we expect other benefits from the virtual field trips such as their use as a preview or review of real field trips.

Of course, virtual field trips have many disadvantages compared to the real thing. Perhaps the most obvious and most serious is that the material presented on a computer is only an abstraction of the real thing. This means that just as viewing a photograph does not give the sense of being in the scene that that photograph shows, being on a virtual field trip does not have the same impact as a real field trip. In general, on a computer, locations and objects are seen via digitized photographs (sometimes using panoramic or "VR" technology) that are two-dimensional representations of the real location or object. They do not and cannot convey the true three-dimensional nature of the location or object, nor convey the touch-texture, smell or a myriad of other subtle clues that aid us to interpret information in the field. This is a general feature of computers, they present a simplified version of real things. Simulations and computer models are just that: simplified attempts to mimic real-world behavior. Another offshoot of this problem of the lack of complexity of computers, is that they do not interact with people in a flexible manner. So whereas computers excel at calculations, their ability to react to natural language, gestures, and ambiguous questions is likely to remain poor for some time to come. Therefore, a virtual field trip must have answers to all expected questions preprepared, and a clearly delineated method to give the computer instructions for completing the virtual field trip. In other words, there is limited give-andtake interaction with a computer, in contrast to real field trip leaders and participants. Often the serendipitous nature of discovery on real field trips is one of the most attractive things about them.

During the creation and evaluation of the existing prototype "field trips" we learned a great deal that prepared us to begin integrating these trips into an Introductory Geology course. Several years of computer "field trip" iterations have shown what framework is needed to contain and display the data, how to provide a way for both regular users and novices to navigate through the "field trips", and how to create interesting interactive computer exercises.

The field trips described above usually consist of several windows, each presenting different kinds of data such as maps, sections, photomicrographs, and pictures. Some of the cross-sections may be animated and images might be drawn on, blown-up or enhanced interactively by the user. There are road maps through the field trip with active buttons that link the various pieces together in various ways depending on the context. Flow charts and other visual organizational cues are also used to guide one through the trip. A separate window is used for note taking, answering and reporting conclusions.

In the prototype "field trips" a variety of exercises were included ranging from simple questions with pop-up answers to somewhat more complicated assembling of geologic maps and sections. We are trying to include a larger number of simulations where the user has controls that manipulate and change the simulation outcome. For example, the Yellowstone field trip has a simulation where the user may change the heat and water input to a gey- 
ser system to see what changes occur. Or, a student may want to try melting and then crystallizing some rocks to see what effect partial melting or fractional crystallization has on the composition of his/her rocks. We also have implemented a series of simple tools such as a measuring stick, a thermometer and a dating tool that allow the student to measure thickness of units, calculate the stream gradients, determine the throw of normal faults, the temperature of a lava flow, etc. We try to avoid "hard-wiring" specific questions and simple quizzes into the computer database, instead leaving those for the instructor to use as needed.

\section{EVALUATION AND ASSESSMENT}

The evaluation of the benefits produced by this project occurs in two parts: (1) ongoing evaluation of each of the case studies as they are implemented with the goal of refining and improving the presentation and scientific content of each computer "field trip" and the integration of them with the appropriate supplemental materials and exercises and, (2) an attempt to measure the benefits of the computeraided case studies as integrated into an introductory geology course vs a similar course using more traditional laboratory exercise. Part one is primarily concerned with the qualitative aspects of the field trip software and case-study exercises as measured by surveys and observations of faculty and students using the software and doing the exercises. This ongoing feedback improves the appearance of the presentation, the clarity of the geologic principles conveyed, the enjoyment of using the software and the means of testing student increase in knowledge and abilities subsequent to completing the project. Part two is concerned with assessing the quantitative benefits of the case studies. The quantitative evaluation of field-oriented instruction is particularly difficult because many, if not most, field interpretations of geologic structure and meaning are non-unique. Owing to inadequate exposure and complicated episodic events, the rock record in the field is often subject to multiple interpretations of its history even by similarly educated experts. Therefore, arbitrary measures of learning such as standardized tests have limited value in assessing benefits of field oriented instruction. Instead we try to concentrate on evaluating the improvement in geologic skills such as creation and interpretation of reasonable geologic maps, ability to infer reasonable geologic mechanisms across large changes in scale and time and, ability to visualize three-dimensional structure from two-dimensional data. We hope to measure increased ability by evaluating geologic map interpretation, a skill incorporating requirements for acute observations as well as inferences. We also hope to measure faster learning of these same skills. In some cases, the benefit of the field trips is that the teacher is able to discuss topics that he was not able to get to before, or discuss them in more detail, because of the experience provided by the virtual field trip.

Assessment requires some type of comparison. To start, we organized several laboratory sections into pilot sections that experienced the field trips and control sections that did not. Both groups were tested at the beginning and end of the semester with a test that hopefully focused on understanding geologic principles and processes. Teaching assistants and lecturers were surveyed on both their impression of the utility of the course and whether the course changed their ability to discuss geologic topics in class.

Because of scheduling difficulties and other logistic problems we were able to perform this controlled test with only 4 sections totaling about 60 students. Preliminary results showed no significant differences between the students' performance on the test. We attribute this to the low number of students involved and the choice of test and test questions. Because of standardization and time constraints, we used a 50 question multiple-choice test. We feel that this type of test is inadequate to assess properly the learning that occurs on a field trip, real or virtual, but it was the best that we could do given time and money constraints.

\section{LESSONS LEARNED}

The preparation of virtual field trips is an iterative, time-consuming process requiring significant commitment from the course lecturer, teaching assistants, course designers, and software developers. In addition, the integration into the introductory laboratory as part of a case study approach requires much additional time and forethought. Our experiment in giving away the prototypes in return for feedback showed us that teachers did not have time to experiment with or evaluate the field trips in their curricula. Of the one hundred CDs that we distributed the first year, only two people returned evaluation forms.

Students learn the most when they are actually assigned to create a virtual field trip. We asked some students to create the hypermedia field trip rather than a typical report. The results were generally excellent although the time required was significantly greater than they would have spent on a written report. However, along the way, they learned about image processing techniques, programming techniques and data handling, as well as about the geology of their field area. Even students with no previous programming skills were able to create visually interesting field trips when we provided a simple template. Most also added some simple graphical exercises. 
We learned to keep the computer interface simple. Too many options confuses the user and puts too many buttons or other controls on limited screen space. Although a good graphic designer/ artist is a necessity, the focus should be on the geologic diagrams, animations and data and not on good looking buttons and window dressing. Ultimately, the computer should recede into the background and not get in the way of the presentation of the data.

\section{NEXT STEP}

We are currently modifying the virtual field trips to take advantages of new technology (such as QuickTime VR (IM) and to be compatible with a web delivery system. At present, the animations, digitized video and QTVR presentations are too slow to effectively manage over a network so we plan to continue using CD-ROM and disk-based modules. We are changing the navigation in the field trips from one where the user typically clicks an arrow button to go to the next scene, to one where the user navigates by clicking on areas within a panoramic picture or scene. In these modules, there is both a map of the area and a QuickTime VR panoramic image on the screen at the same time. They are linked together so that the view in the panorama is indicated on the map. The user may zoom in on the scene and click on various spots on the image indicated to him by a change in the cursor. Some of these hotspots jump the scene to another panorama and map. Others allow the user to "pick up" and rotate a sample. Still others show a video, animation or exercise for the student. Typically, a small explanatory text window with information about the current scene is kept updated. Users can drag images, text and movies to a notebook window to aid in assembling a report, or just to keep bookmarks into an important place in the field trip. The notebook is also used to type in their own observations and interpretations.

Here at University of Illinois the Introductory Geology Laboratory takes a short one period field trip around the nearby buildings to learn about and identify stone used for building and decorative purposes. We have built a local virtual field trip around these building and other buildings near the campus for the students to use as review and reinforcement. Although we are not allowed to drop acid on, or scratch the rocks on the real field trip, we have taken video of similar rocks being treated with acid and being scratched and incorporated the video into a Web and Java based field trip. Students can access the virtual field trip from our Web site and look at parts of campus that they did not get to see during the one $50 \mathrm{~min}$ class period.

\section{CONCLUSIONS}

The overall goal of our development of "virtual" field trips is to educate the public about how scientists in general, and geologists in particular, practice their discipline, to teach methods as much as content. This project is based on the idea that students can and should learn about geology by understanding field relationships, and that enough of those field observations can be captured to a computer providing a meaningful database. It integrates the collection, analysis and discussion of data in a manner that facilitates understanding and exploration. The computerized field trip also makes it possible for students to visit and learn from field areas far removed from their usual range, whether that is Iceland, the sea floor or the Moon. In addition to the educational market, these virtual field trips are appropriate for the interested tourist who wishes to learn a little more deeply what the geologic background is for areas for which we have created the field trip.

Example movies, field trips and more information can be obtained by following the links at: 〈http://www.geology.uiuc.edu/HTML/SHurst/ fieldtrp.html $\rangle$.

Acknowledgments - I would like to thank Richard Strelitz who helped form the original idea for these field trips and Ronald Perkins and Jeff Karson, my co-Principal Investigators on the original proposal to FIPSE. I also would like to thank all the TAs, students and faculty who helped create, edit, and evaluate the programs. I also thank Paul Fullagar at University of North Carolina and Patchin Curtis who were also my collaborators and contributed greatly to this project. The work was supported by a Grant from the FIPSE program of the Department of Education and from NSF-DUE grant \#96-96213.

\section{REFERENCES}

Condit, C. D. (1995) DDM-SVF: A prototype dynamic digital map of the Springerville Volcanic Field, Arizona. GSA Today 5(4), 69-88.

Harper, T. (1990) Hypercard and Videodisc: a case study in design. In Learning with Interactive Multimedia, ed. S. Ambron and K. Hooper, pp. 331-348. Microsoft Press, Redmond, Washington.

Hurst, S. D., Perkins, R. D. and Karson, J. A. (1992) Interactive computerized geologic field trips as case studies for geologic instruction. Geological Society of America 24, A131 Abstracts with programs.

Kulik, J. A. (1994) Meta-analytic studies of findings on computer-based instruction. In Technology Assessment in Education and Training, ed. E. L. Baker and H. F. O'Neil, pp. 9-34. Lawrence Erlbaum Associates, Hillsdale, New Jersey.

Roper, S. D., The Vesalius Project. Academic Computing, October 1989, 16. 